\title{
Modality Effects in Reducing Cognitive Loads in Multimedia Learning
}

\author{
Dr. Osamah Aldalalah \\ Department of Educational Technology. Jadara University- Jordan
}

Accepted: February 10, 2012 Published: March 17, 2012

Doi:10.5296/ijld.v2i1.1522ＵRL: http://dx.doi.org/10.5296/ijld.v2i1.1522

\begin{abstract}
The purpose of this study was to investigate the effects of modality principle on the learning of music theory among primary pupils in Jordan. The lesson of music theory was developed in two different modes, audio and image (AI) and text with image. A quasi experimental factorial design was adopted in this research. The independent variables were the two modes of courseware. The dependent variable was the post test score. The study sample consisted of 269 third-grade pupils and were randomly (simple random sample) selected from six different primary co-education schools. Descriptive and inferential statistics were conducted to analyze the collected data. T-test was used to determine the significant differences of the pre-test scores among the groups. Analyses of covariance (ANCOVA) were carried out to examine the main effects as well as the interaction effects of the independent variables on the dependent variables. The findings of this study showed that pupils using the AI mode performed significantly better than those in the TI mode. Apparently, the cognitive loads in the visual and audio working memory were reduced to facilitate increased capacity for better learning.
\end{abstract}

\section{Introduction}

The Cognitive Theory of Multimedia Learning (CTML) is a computer-based, multimedia instructional design theory that uses three assumptions (Mayer, 2010): the dual-channel, limited-capacity, and the active processing assumptions. The dual-channel assumption is based upon researches conducted by Baddeley (1992) and Paivio (1986) and assumes that learners possess two information-processing channels: one channel that processes visual information and another that processes verbal information. By utilizing both channels, learners are given the opportunity to build both verbal and visual mental models. According to Mayer (2001) humans can only process a finite amount of information in a channel at a time, and they make sense of incoming information by actively creating mental representations. Mayer also discusses the role of three memory stores: sensory (which receives stimuli and stores it for a 
very short time), working (where we actively process information to create mental constructs (or 'schema'), and long-term (the repository of all things learned).

Mayer's cognitive theory of multimedia learning presents the idea that the brain does not interpret a multimedia presentation of words, pictures, and auditory information in a mutually exclusive fashion; rather, these elements are selected and organized dynamically to produce logical mental constructs. Furthermore, Mayer underscores the importance of learning (based upon the testing of content and demonstrating the successful transfer of knowledge) when new information is integrated with prior knowledge Figure 1.

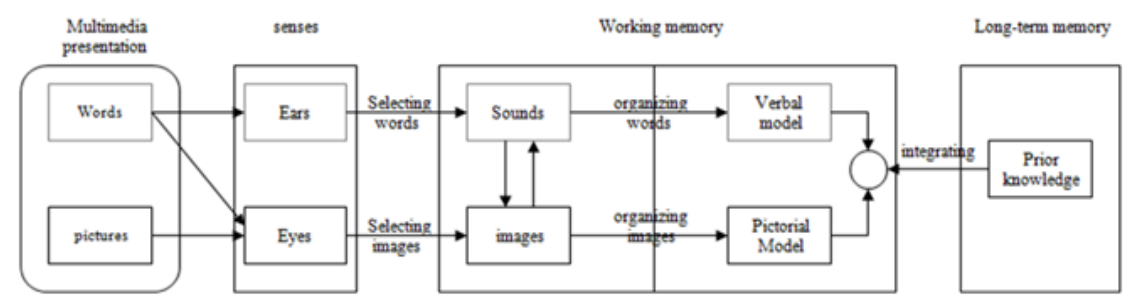

Figure 1 Cognitive Theory of Multimedia Learning (Mayer, 2001)

Design principles including providing coherent verbal, pictorial information, guiding the learners to select relevant words and images, and reducing the load for a single processing channel etc. can be entailed from this theory. In this model, the learner selects some information, organizes it and integrates it with prior knowledge. Here, the focus is on the importance of two different kinds of information construction among learners:

Making connections between the different parts of perceived information.

Making connections between the different learners' prior knowledge.

As such, understanding is not the result of transforming or storing information in memory; rather, understanding is the result of making connections and building relationships between information components and prior knowledge to acquire new learning. In fact, Mayer's

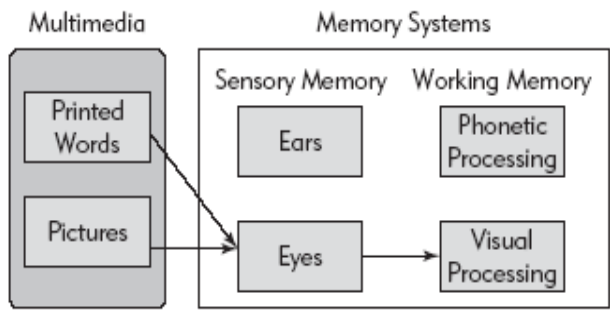

Multimedia Principle states that "students learn better from words and pictures than from words alone" Figure 2 (Mayer, 2001)

Figure 2 Words and Picture Processing (Mayer, 2001) 


\section{Music Theory}

Many scholars such as Aldalalah \& Fong (2010a) define music theory as the area in which music works are studied. It mainly deals with the language and notion of music where it is composed and interpreted. It assists to categorize the various music patterns and structures experienced in the process of composition throughout genres, styles or during historical periods. According to Chew (2005) music is a language that possesses both universal context and notations. On the other hand, Fong \& Aldalalah (2010a) argues that music provides a unique structure for musicians to reveal their musical concepts. This is because it focuses on music notation is composed in terms of the components of the notation. Also, it involves basic musical concepts that may be observed in forms of the structure, the organization and the history (Smith, 2009). These musical concepts have an important role in establishing the necessary knowledge for interpreting the development stages in music and the mode in which the notation is utilized in various situations. Wilson (2005), Mcvay (2004) and Guderian (2008) conducted a study to investigate the difficulties that students face when reading a music theory. The findings of their work revealed that many students face problems when it comes to interpreting and reading a music theory (Aldalalah, \& Fong, 2010b). This results in learning music. Also, the findings of their research led many Arab countries to revise and review their music curriculum to improve music theory learning in an educational context (Fong \& Aldalalah, 2010b; Yagmor \& Aldalalah, 2007).

\section{Modality principle}

Moreno \& Mayer (1999) suggested that pictures should go together with a synchronized auditory explanatory recitation rather than a synchronized explanatory text, (see Figure 3).

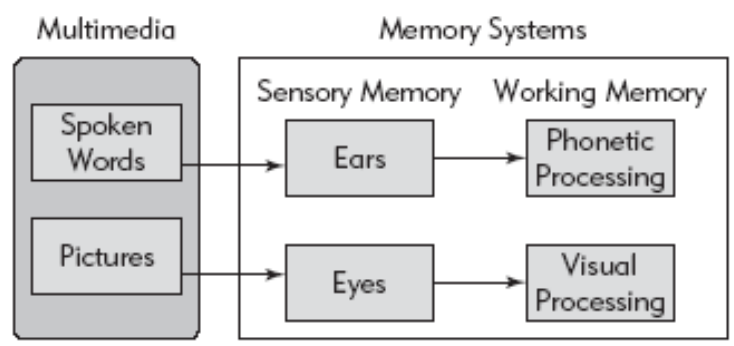

Figure 3 Modality Principle (Clark \& Mayer, 2008)

Zheng, McAlack, Wilmes, Kohler-Evans \& Williamson (2009) found that the learner's understanding when watching animated images on a certain phenomenon accompanied with an auditory explanation is much better than the learner's understanding when watching animated images on the same phenomenon while verbally reading an onscreen-text explanation. At the same time, this principle is in tandem with the cognitive learning theory using multimedia techniques (Seufert, Schu \& Nken, 2009). The cognitive theory of multimedia learning suggests that reading an onscreen-text along with animated pictures will result in interference in the rendered information especially when this information is to be processed verbally (Mayer, 2010). However, this will add more load on the visual working memory because both are addressed in the form of verbal memory and in visual approach while the auditory text is processed in the verbal model and audio working memory (Harskamp, Mayer \& Suhre, 2007; Pazzaglia, Toso \& acciamani, 2008). Furthermore, animated images are 
processed in the visual model, thus, providing an auditory text along with watching an explanatory film that does not overlap (Wouters, Paas, Jeroen \& Merrienboer, 2009). Therefore, this also fits the modality principle by combining the visual channel for graphical material and the verbal channel for the explanation of this material to increase the working memory capacity effectiveness and facilitate learning (Moreno, 2006; Dempsey \& Eck, 2003).

\section{Methods}

\section{Population Sample}

The population of this study comprised all third grade primary pupils (2263) enrolled in the ALKORAH educational directorate in Irbid Governorate (Jordan) in the second semester of the 2008/2009 academic year. The sample consisted of 269 pupils who studied in third-grade classes and were randomly selected from six different primary co-educational schools. According to Gay and Airasian (2003) "all the individuals in the defined population have equal and independent chance of being selected". The six schools were also randomly selected from the primary schools where music was taught in heterogeneous classes with no grouping or ability tracking.

\section{Experimental Condition}

The pupils' distribution within the treatment groups was conducted randomly. Then the treatment groups were exposed to the treatment consecutively. The two treatment groups are as follows:

First treatment: The educational material was shown as images and audio.

Second treatment: The educational material was shown as text and images.

\section{Instruments}

The music achievement test that was administered on the participants of the two groups in this study is adapted from the music theory competency test developed by the researchers. The music theory competency test consisted of 15 recall (remembering) and 15 understanding items.

\section{Music achievement test Reliability}

To ensure the reliability of the music achievement test, the researchers checked the reliability of the instrument with a Test-Retest (Tuckman, 1999) where it was applied on the pilot study samples. The 30 items were divided into two parts; the reliability of the test questions was calculated using the Cronbach Alpha procedure to calculate the internal consistency. The Cronbach Alpha of the first and second parts was 0.81 and 0.82 respectively. The Cronbach Alpha of the test was 0.80 . All of them were found to be reliable. The internal consistency of the first part was 0.86 and that of the second part was 0.88 . Overall, internal consistency of the parts was 0.93 .

\section{Difficulty and Discrimination Coefficients}

Difficulty values ranged from $0.31-0.66$, and discrimination coefficients ranged from $0.45-0.98$; both were found to be acceptable for the purposes of this study. 
Instruments Validity

2012, Vol. 2, No. 1

Validity of the instruments is important aspects that should be taken into account when conducting a research. Validity consists of two different aspects that are face and content validity. According to Gay and Airasian (2000) face validity relates to "the degree to which a test appears to measure what it claims to measure" . Face validity was judged by a panel of experts in the field of education and music. Content validity refers to the "degree to which a test measures an intended content area" (Gay and Airasian, 2000). Content validity of the instruments in this research was justified by the panel. The panel of experts comprised 2 specialists in the field of educational technology; 1 specialist in curricula and teaching methods, 2 specialists in music education, a supervisor of music activity in the ALKORAH education directorate; 2 members of the National Team For The Development of Music Curriculum, 2 specialists in Psychology, 2 specialists in primary education, 1 specialist in computer science, 1 specialist in measurement and evaluation, and 2 music teachers who have Masters degrees and a remarkable teaching experience in Jordan, each teacher has a minimum of four years of teaching experience in the Jordanian Ministry of Education. The instruments were evaluated during and after the development of the research study. The feedback and comments received from the panel of experts were employed to establish the necessary clarifications, changes, and modifications before and after piloting the study.

\section{Study Design}

This study followed the quasi experimental method to measure the impact of the 2 modes of treatments on the post test scores of the third grade pupils in the music classes.

\section{Research Variables}

The present research contains two types of variables (independent and dependent variables) that are presented as follows:

Independent Variables

The independent variables in this study were the two modes of presentation:

Multimedia computer-based learning courseware with music theory presented in audio and text (AI)

Multimedia computer-based learning courseware with music theory presented in text and image (TI)

Dependent Variable

Post Test Scores (learning)

\section{Results}

The analyses of the collected data were carried out through various statistical techniques such as the t-test, ANCOVA, The data were compiled and analyzed using the Statistical Package for the Social Science (SPSS 16) for Windows computer software.

The Pre-Quasi Experimental Study Results 
The purpose of the pre-quasi experimental study was to test the assumption that the participants across the two groups were equivalent in their prior knowledge of the unit on music theory for third grade primary pupils. To test that the participants across the two groups were equivalent, the pre-test was conducted four weeks before the beginning of the study. The pre-test papers were scored by the researcher. To determine if there were statistically significant differences between the groups' mean scores, the scores of the two groups were entered into the Statistical Package for Social Science (SPSS 16) for Windows computer software.

\section{Measure of Relationship between Pre-test Scores and Post-test Scores}

A correlation coefficient of $\mathrm{R}=0.573 * *$ indicates a high positive relationship between the two variables.

\section{Testing the two groups' equivalence}

To examine the equality of treatment mode on the pre-scores, the t-test procedure was used. The $\mathrm{p}$ values $=0.108$ showed that there is no significant difference in the pre-test scores among the two treatment groups. This means that the two groups have the same level of prior knowledge of the unit on music theory for third grade primary pupils.

\section{Testing Homogeneity of Variances for the Variables in the Pre-test and post-test}

The results from Levene's Test for homogeneity of variance by comparing the dependent variables across the two groups for Treatments indicated homogeneity of variance was met by all the dependent variables. As $\mathrm{p}>0.05$ for all variables, the results show that the groups were homogenous.

Testing of Normality of Distributed Pre-test and post-test

A skewness range and kurtosis range presented values reveal that the variables are normally distributed and have met the criteria for further analysis.

\section{Description of the Post-test Scores of Pupils in Various Treatment Groups}

Comparison was made between group AI and TI, based upon the mean of the post-test scores (Table 1). It showed a difference between the means of the post-test scores for groups using the AI mode and TI mode. The mean of post test scores for groups using the AI mode (25.17) was higher than the mean of post-test scores for the group using the TI mode (16.82).

Table 1: Post-test Score of Pupils in Various Treatment Groups

\begin{tabular}{llll}
\hline & & Std. & \\
Groups & Mean & Deviation & $\mathrm{N}$ \\
\hline AI & 25.1719 & 3.35817 & 128 \\
TI & 16.8227 & 3.77072 & 141 \\
Total & 20.7955 & 5.49754 & 269 \\
\hline
\end{tabular}


The correlation coefficient $\mathrm{R}=0.573 * *$ indicated a high positive relationship between the pre-test scores and the post-test scores. In order to reduce the statistical error, the pre-test scores were used as the covariate variable and a comparison was made among the two groups (AI \& TI) using the ANCOVA procedure (Table 2).

Table 2 ANCOVA of the Post-test Scores of Pupils in Various Treatment Groups

\begin{tabular}{llllll}
\hline \multicolumn{2}{l}{ Type III Sum } & & & \\
of Squares & df & & Mean Square F & Sig. \\
\hline $\begin{array}{l}\text { Corrected } \\
\text { Model }\end{array}$ & $6709.528 \mathrm{a}$ & 2 & 3354.764 & 641.886 & .000 \\
Intercept & 1225.729 & 1 & 1225.729 & 234.526 & .000 \\
pre & 2032.560 & 1 & 2032.560 & 388.901 & .000 \\
Groups & 4048.536 & 1 & 4048.536 & 774.630 & .000 \\
Error & 1390.226 & 266 & 5.226 & & \\
Total & 124430.000 & 269 & & & \\
Corrected Total & 8099.755 & 268 & & & \\
\hline
\end{tabular}

The values $F(1,266)=774.630$, Mean Square $=4048.536$, and $p=.000$ show a significant difference between the post-test scores of pupils using AI mode and pupils using TI mode.

\section{Discussions}

This study found that pupils using AI mode learn better compared to pupils using the TI mode. There are several reasons for this result. A possible reason for the significantly positive effect of modality principle on pupils' learning can be explained by Mayer's (2001) cognitive theory of multimedia learning. The cognitive theory of multimedia learning proposed that the human information processing system comprises dual channels, that is, one for visual processing and the other for auditory processing. When information is presented to the eye (image and text), learners begin by processing that information in the visual channel; when information is presented to the ears (audio), learners begin by processing that information in the auditory channel. According to Mayer (2001) learners have a limited capacity in the amount of information that can be processed in each channel at any one time. In this way the information processed through the two channels are balanced, that is, neither one of the channel is cognitively overloaded. The picture enters through the eyes (and is processed in the visual / pictorial channel) while the spoken word enters through the ears (processed in the auditory / verbal channel).

The modality effect is believed to be caused by visual channel overload and split attention effect. When texts and images are presented visually, texts exert extraneous load on the working memory because they use the visual channel, at least initially, before the information is transmitted to the auditory channel. On the other hand, auditory texts enter the auditory channel directly, thus, releasing the visual channel from any unnecessary load. From a cognitive load theory perspective, the modality effect is such that when the image is presented 
with the text a higher cognitive load is induced in the visual working memory as both sources of information are processed in the same visual channel of the working memory.

A split attention effect occurs because visual attention has to be spread between visual texts and pictures which must be integrated mentally to achieve comprehension. This means, for example, that learners must search for corresponding information from the texts and pictures which also often results in less relevant materials being selected for further processing (especially with system-paced instructions including dynamic presentations), and keep it concurrently in the working memory to enable integration processes to take place. Splitting attention exerts a heavy extraneous load on the working memory. With auditory texts, no splitting of attention is necessary. A simultaneous audio-visual presentation increases the likelihood of learners being able to select relevant information from the texts and pictures and to retain corresponding words and pictures in the working memory at the same time. Thus, it is also more likely that learners engage in active meaningful learning, particularly in integrative processing of verbal and pictorial information. This study found that pupils using AI mode learn better compared to pupils using the TI mode. There are several reasons for this result.

A possible reason for the significantly positive effect of modality principle on pupils' learning can be explained by Mayer's (2001) cognitive theory of multimedia learning. The cognitive theory of multimedia learning proposed that the human information processing system comprises dual channels, that is, one for visual processing and the other for auditory processing. When information is presented to the eye (image and text), learners begin by processing that information in the visual channel; when information is presented to the ears (audio), learners begin by processing that information in the auditory channel. According to Mayer (2001) learners have a limited capacity in the amount of information that can be processed in each channel at any one time. In this way the information processed through the two channels are balanced, that is, neither one of the channel is cognitive overloaded. The picture enters through the eyes (and is processed in the visual / pictorial channel) while the spoken word enters through the ears (processed in the auditory / verbal channel).

It may result from the modality effect on pupils' music theory learning. The modality principle is that pupils learn more deeply from AI than from TI. According to the modality principle, pupils using the AI mode are expected to learn better than pupils using the TI mode. According to the cognitive theory of multimedia learning, the processes required for learning cannot be fully achieved when the visual channel is overloaded, that is, when pupils using the TI mode do not learn better compared to pupils using the AI mode.

It could be that the image and text (TI) compete for limited cognitive resources in the visual channel because both enter the information processing channel through the eyes. In such a condition, visual image together with the printed written text may result in an overload in the visual channel while the auditory channel remained unused. This will affect the processing of information. Moreover, pupils using the TI mode (printed text and image) had to split their attention between the two information sources (Clark \& Mayer, 2008). They had to switch their 
attention back and forth between the printed text and image which occupied much cognitive load to process the switching.

\section{Conclusions}

This study found that the use of Audio-Image (AI) treatment mode helped pupils perform significantly better in learning music theory. It gives support to the effect of modality principle on the learning of music theory. In other words the AI treatment mode showed a significant effect on the conceptual understanding and remembering of music theory. In short, the study strongly indicated that a modality principle was effective in promoting better learning of music theory. Seemingly, the instructional design of the AI treatment effectively reduces the cognitive overload in the working memory and hence improve information processing and learning.

\section{References}

Aldalalah, $O$ \& Fong, S. F. (2010a). Effects of Modality and Redundancy Principles on the Learning and Attitude of Music Theory among Primary Pupils in Jordan. International Education Studies, 3(3) (in press)

Aldalalah, $O \&$ Fong, S. F. (2010b). Effects of computer-based instructional designs among pupils of different music intelligence levels. International Journal of Social Sciences, 5(3), 168- 176.

Baddeley, A. (1992). Working memory. Science, 255 (5044), 556 - 559.

Chew, D. (2005). Computer-assisted instruction for music theory education: Rhythm in music. PhD Thesis (Unpublished), California state university.

Clark, J. M. \& Mayer, R. (2008). E-learning and the science in instruction. San Francisco: Pfeiffer.

Dempsey, $J \&$ Eck, R. (2003). Modality and placement of a pedagogical adviser in individual interactive learning. British Journal of Educational Technology, 34(5), 585-600.

Fong, S. F \& Aldalalah, O. (2010a). Modality and redundancy effects on music theory learning among pupils of different anxiety levels. International Journal of Behavioral, Cognitive, Educational and Psychological Sciences, 2(3), 167- 175.

Fong, S. F \& Aldalalah, O. (2010b). Computer-based Instructional Design in Music Theory Learning among Internals-Externals: A cognitive load perspective. European Journal of Social Sciences, 13(5), (in press).

Gay, L. R. \& Airasian, P. (2000). Educational research: Competencies for analysis and application (6th ed.). Upper Saddle River, NJ: Merrill.

Gay, L. R. \& Airasian, P. W. (2003). Educational research: Competencies for analysis and application (7th ed): Prentice Hall.

Guderian, L. (2008). Effects of applied music composition and improvisation assignments on sight-reading ability, learning in music theory and quality in soprano recorder playing. Ph.D Thesis (Unpublished), Northwestern University.

Harskamp, G. E., Mayer R. E. \& Suhre, C. (2007). Does the modality principle for multimedia learning apply to science classrooms?. Learning and Instruction, 17 (5), 465-477. 
Mayer, R. E. (2010). Merlin c. Wittrock's enduring contributions to the science of learning. Educational Psychologist, 45(1), 46-50.

Mayer, R. E. (2001). Multimedia learning. New York, Cambridge university press.

Mcvay, $V$. (2004). The effectiveness of color-coding for learning music theory rudiments, aural skills, and keyboard skills in persons aged in 60 and older. Ph.D Thesis (Unpublished), University of Kentucky.

Moreno, R. (2006). Does the modality principle hold for different media? A test of the method affects learning hypothesis. Journal of Computer Assisted Learning, 22(3), 149-158.

Moreno, R. \& Mayer, R. E. (1999). Cognitive principles of multimedia learning: The role of modality and contiguity. Journal of Educational Psychology, 91(2), 358-368.

Paivio, A. (1986). Mental presentations a dual coding approach. Oxford science publication.

Pazzaglia, F., Toso, C. \& Cacciamani, S. (2008). The specific involvement of verbal and visuospatial working memory in hypermedia learning. British Journal of Educational Technology,39(1), 110-124.

Seufert, T., Schu, M. \& Nken, R. (2009). Memory characteristics and modality in multimedia learning: An aptitude treatment interaction study. Learning and Instruction, 19(1) 28-42.

Smith, K. H. (2009). The effect of computer-assisted instruction and field independence on the development of rhythm sight-reading skills of middle school instrumental students. International Journal of Music Education, 27 (1), 59-68.

Tuckman, B. W. (1999). Conducting educational research. 5th edition. Orlando: Harcourt Brace College Publishers.

Wilson, T. C. (2005). An implementation of a drill and practice system to assist in the teaching of basic music theory. Master Thesis (Unpublished), Brigham Young University.

Wouters, P., Paas, F., Jeroen, J. \& Merrienboer, V. (2009). Observational learning from animated models: Effects of modality and reflection on transfer. Contemporary Educational Psychology, 34(1), 1-8.

Yagmor, K. \& Aldalalah, O. (2007). How teachers grade students acquire basic skills necessary to teach songs of the three first and attitudes toward it. South Valley University Journal, 21(2), 17-32.

Zheng, R., McAlack, M., Wilmes, B., Kohler-Evans, P. \& Williamson, J. (2009). Effects of multimedia on cognitive load, self-efficacy and multiple rule-based problem solving. British Journal of Educational Technology, 40(5), 2009 790-803. 